\title{
Outstanding Reference Sources 2015
}

\section{The Outstanding Reference Sources Selection Committee}

The Outstanding Reference Sources Selection Committee consists of Curtis Ferree (chair), Fairfield University; Shelley Arlen, University of Florida, Gainesville, Florida; Julie Elliot, Indiana University-South Bend; Annie Fuller, St. Louis County Library; Adam Jackman, Pierce County (WA) Library; Alec Sonsteby, Metropolitan State University, St. Paul, Minnesota; Kathi Woodward, The Library Center, Springfield, Missouri; Jessica McCullough, Connecticut College, New London, Connecticut; Stephanie Alexander, California State University, East Bay.

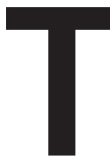

he Outstanding Reference Sources Committee was established in 1958 to recommend the most outstanding reference publications for small and medium-size academic and public libraries. All titles considered for nomination were published between November 2013 and December 2014.

The 2015 winners are:

American Indians at Risk. Jeffrey Ian Ross, editor. Greenwood (ISBN: 9780313397646).

Black Stats: African Americans by the Numbers in the TwentyFirst Century. Monique W. Morris. The New Press (ISBN: 1595589198).

Bumblebees of North America. Paul Williams, Robin Thorp, Leif Richardson, and Shelia Colla. Princeton University Press (ISBN: 0691152225).

Consumer Healthcare. Brigham Narins, editor. Gale Cengage Learning (ISBN: 1573027251).

Dictionary of Untranslatables: A Philosophical Lexicon. Barbara Cassin, editor. Translation edited by Emily Apter, Jaques Lezra, and Michael Wood. Princeton University Press (ISBN: 9780691138701).

The Encyclopedia of Criminology and Criminal Justice. Jay S. Albanese, editor. Wiley Blackwell (ISBN:978146145689-6).

The Encyclopedia of Deception. Timothy R. Levine, editor. Sage (ISBN: 9781452258775).

The Encyclopedia of Humor Studies. Salvatore Attardo, editor. Sage (ISBN: 9781412999090).

The Encyclopedia of the Wars of The Early American Republic, 1783-1812. Spencer C Tucker, editor. ABC-CLIO (ISBN: 9781598841565).

Muhammad in History, Thought, and Culture: An Encyclopedia of the Prophet of God. Coeli Fitzpatrick and Adam Hani Walker, editors. ABC-CLIO (ISBN: 978-1-61069-177-2). 